\title{
Some applications of humidity profiles estimated from INSAT infra red digital cloud imagery data
}

\author{
Onkari Prasad, Sant Prasad, Kanti Prasad and R R Kelkar \\ India Meteorological Department, New Delhi, India
}

\begin{abstract}
Moisture profiles have been estimated over the region bounded by the latitudes $40^{\circ} \mathrm{N}$ and $40^{\circ} \mathrm{S}$ and longitudes $30^{\circ} \mathrm{E}$ to $130^{\circ} \mathrm{E}$ using INSAT digital infra red cloud imagery data. The representativeness of these profiles in representing moisture field associated with the development and movement of synoptic scale systems during the period September 15th, 1996 to March 31st, 1997 has been examined. It has been shown that the changes in the moisture field associated with the withdrawal of the southwest and northeast monsoons from the Indian sub-continent, development and movement of synoptic scale sytems (depressions, tropical cyclones and waves in easterlies) and equatorial troughs in the Indian Ocean could be clearly seen in humidity profiles. The initial development of tropical systems is first seen in the humidity field in the upper troposphere. These profiles could be used in monitoring the initial development and subsequent movement of tropical systems. Further the data on moisture distribution from the data gap regions of the Indian Ocean could be used as an additional source of moisture in numerical analysis and prognosis.
\end{abstract}

\section{Introduction}

The non-availability of an adequate number of radiosonde observations from ocean areas causes deficiencies in the analysis of moisture fields. Accurate humidity fields are required for useful short and medium range forecast from numerical models. Digital infra red (IR) cloud imagery data from geostationary satellites are especially suited for estimating moisture in the atmosphere covering large areas of tropics on an operational basis at synoptic hours. Estimation of moisture from digital IR cloud imagery data is based on the premise that an analysis of the equivalent black body temperature of each cloud pixel, which is referred to as cloud top temperature (CTT), in an area co-located with a radiosonde ascent could be used to classify the cloud depth, amount and type in that area, and this cloud classification cloud be related to the dew point depression profile of the radiosonde ascent. At numerical prediction division of the Japan Meteorological Agency (JMA), GMS infra red cloud imagery data have been used for estimation of humidity profiles (Baba 1987). Prasad and Rao (1991) have demonstrated the estimation of humidity profiles from the Indian Ocean region using INSAT IR cloud imagery data. As they have used only a limited period of data for obtaining the profiles, many cloud categories are not represented in the profiles obtained by them. A simplified version of the JMA scheme has been developed at the Bureau of Meteorological Research Centre (BMRC) by Mills and Davidson (1987). The method is relatively simple as it uses a total of only nineteen profiles for representing moisture in the troposphere. An examination of these profiles during the period May-June 1994 (Prasad et al 1996) showed that the profiles are able to clearly delineate the build-up of moisture in the vertical and its northward propagation associated with the onset of the southwest monsoon. In the present paper we have examined these profiles in relation to the development of synoptic scale systems and their movement over the Indian Ocean region. The results are briefly discussed in the following sections. The ultimate aim of examining these profiles is to use them as an additional source of moisture in the numerical analysis for the India Meteorological Department's

Keywords. Humidity profiles; infra red cloud imagery data; INSAT; numerical weather prediction (NWP). 

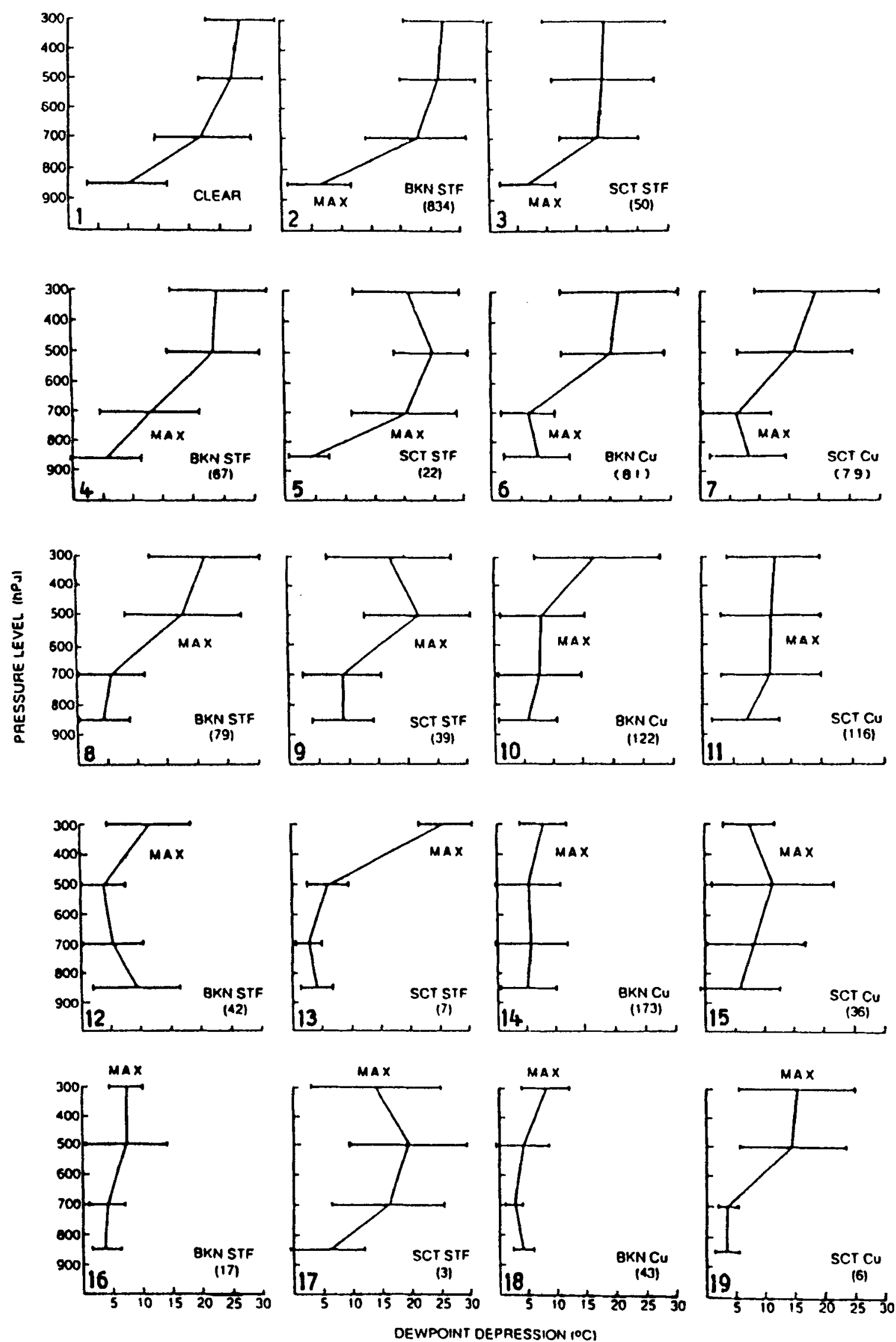

Figure 1. Dew point depression profiles for each of the nineteen cloud categories, together with the type of Cloud (cummuliform $(\mathrm{Cu})$ or stratiform (STF)) whether greater (BKN) or less (SCT) than $50 \%$ cloud cover. Bracketed numbers indicate the number of matchups in each category, while 'MAX' indicate the pressure layer in which the maximum cloud amount resides (after Mills and Davidson 1987). Figures in the bottom left corner indicate the profile number. 


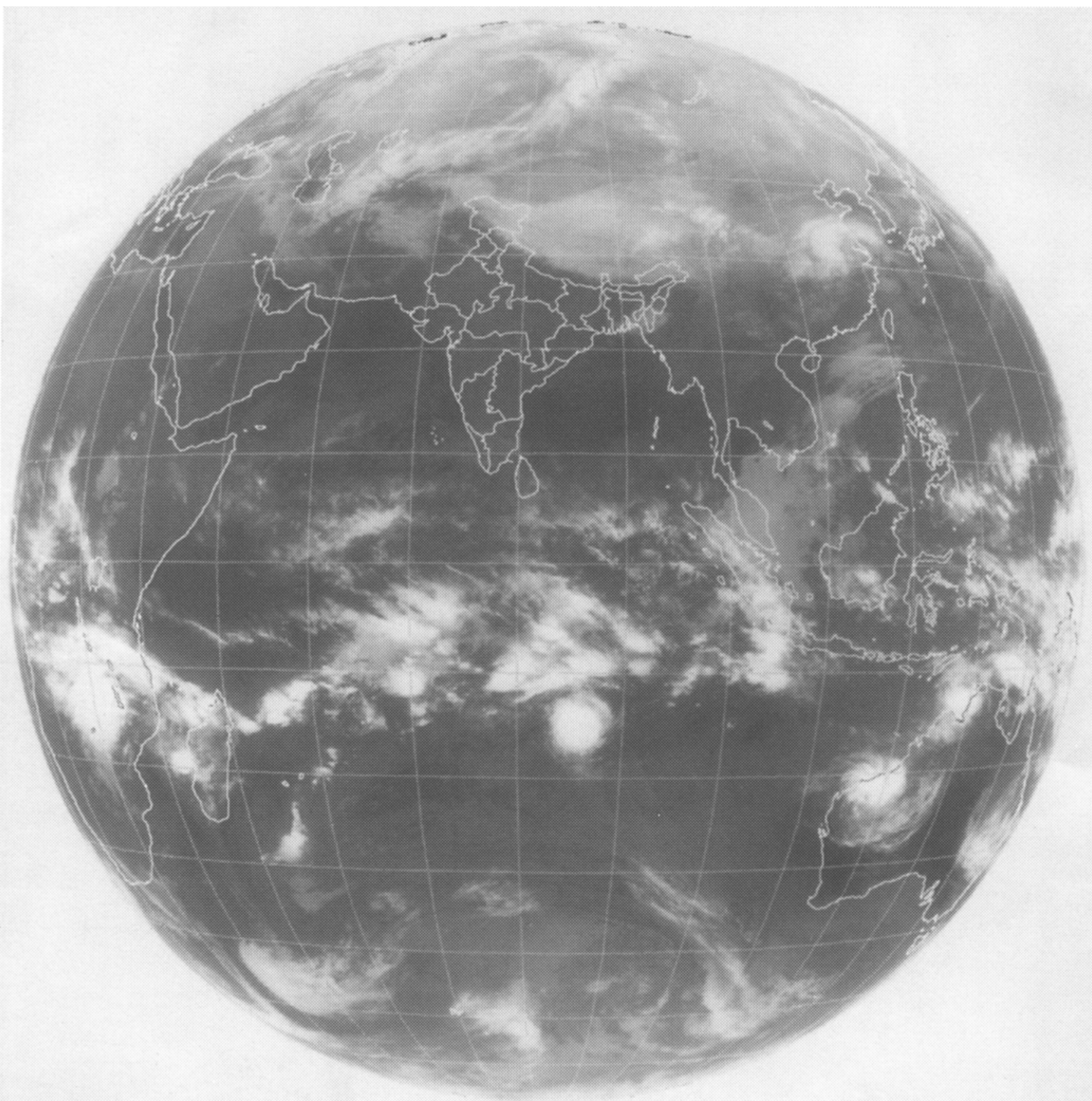

Figure 2. INSAT infra red cloud imagery of 0000 UTC of 1.2.97.

Limited Area Model (LAM) and to examine its impact on predicting development and movement of synoptic scale weather systems and rainfall over India. IMD's LAM is a multilevel primitive equation model which runs in an operational mode on Cyber 2000U computer system.

\section{Data used and method of analysis}

Using the method of Mills and Davidson (1987) humidity profiles (charts of dew point depression in $\mathrm{K}$ at $850,700,500$ and $300 \mathrm{hPa}$ ) for $0000 \mathrm{UTC}$ have been obtained for the period September 15th, 1996 to March 31st, 1997. Only a selected number of dew point depression contours have been drawn on each chart. The contour values are $4,6,8$ and 10 at $850 \mathrm{hPa} ; 6,11,16$ and 21 at $700 \mathrm{hPa} ; 6,13,20$ and 27 at $500 \mathrm{hPa} ; 10,16,22$ and 28 at $300 \mathrm{hPa}$. Out of the 19 profiles available in Mills and Davidson method (figure 1), profile numbers 18,16 and 14 represent the humid profiles. Other profiles represent relatively dry atmosphere. At $700 \mathrm{hPa}$ the value of the dew point depression relating to the humid profiles are 3,5 and 5 respectively. Thus at this level the humid regions are delineated by the dew point depression 


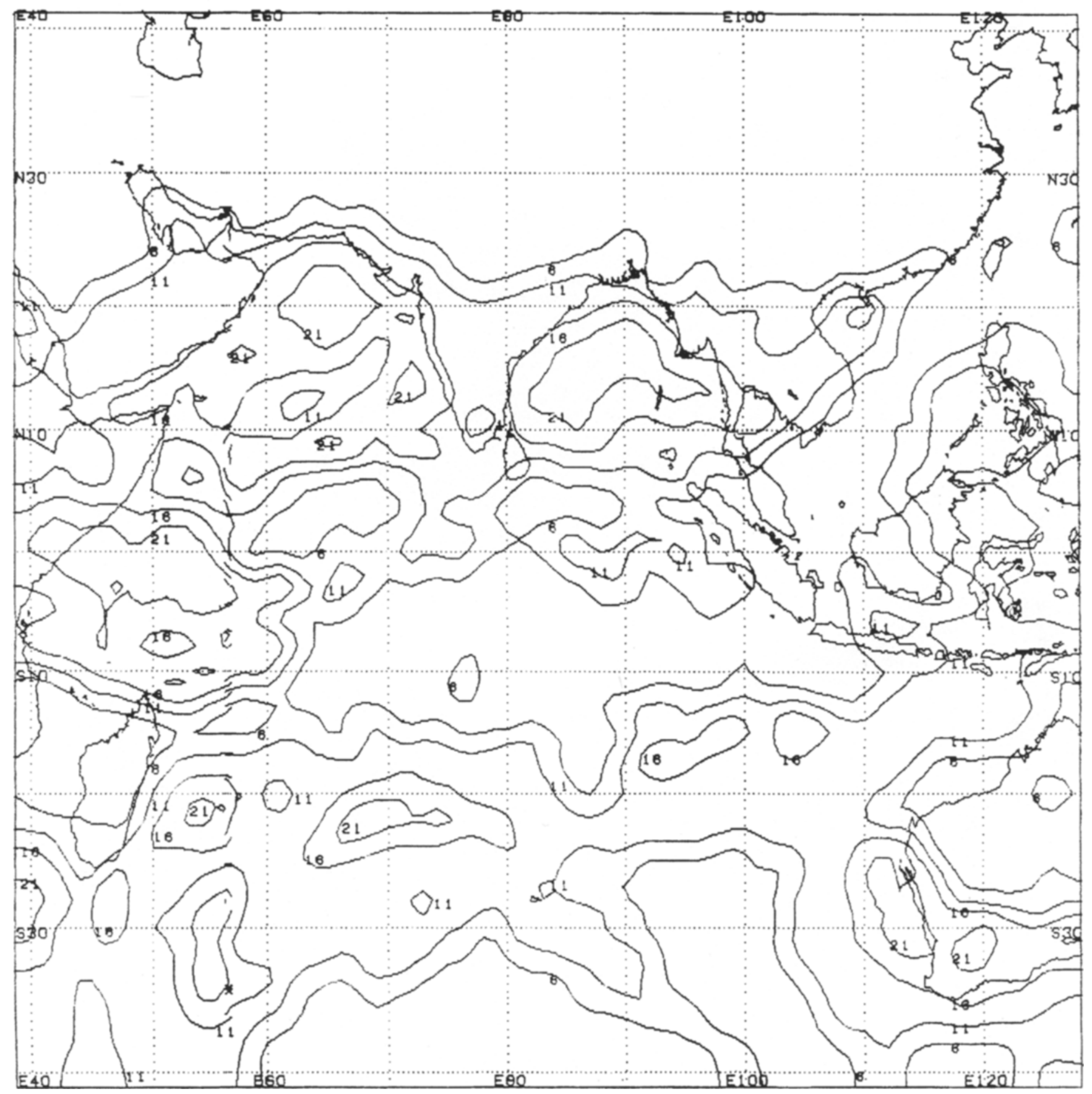

Figure 3. Dew point depression chart at $700 \mathrm{hPa}$ at $0000 \mathrm{UTC}$ of 1.2 .97 .

contour of $6 \mathrm{~K}$. As we move away from the regions of $6 \mathrm{~K}$ dew point depression contours the atmosphere becomes relatively dry. For the purpose of illustration, the full disk INSAT IR picture for 0000 UTC of February 1st, 1997 (figure 2) and $700 \mathrm{hPa}$ dew point depression chart obtained using the digital IR cloud imagery data of this picture are reproduced in figure 3 . We have reproduced charts of $700 \mathrm{hPa}$ only (except in some specific cases) for discussions under section 3 as the tropical systems are best represented at this level. However, the charts of 500 and $300 \mathrm{hPa}$ level could also be used for the purpose of discussion as moisture generally extends up to upper troposphere in tropical regions in association with synoptic scale systems. The picture is different at $850 \mathrm{hPa}$ as moisture is generally high over larger areas around the synoptic systems. The humidity profiles discussed below include the following situations:

- Withdrawal of southwest and northeast monsoons 1996

- Development and movement of synoptic scale system in the Bay of Bengal and Arabian Sea during northeast monsoon:

- Cyclonic storm in the Arabian Sea (22nd-27th October, 1996). 

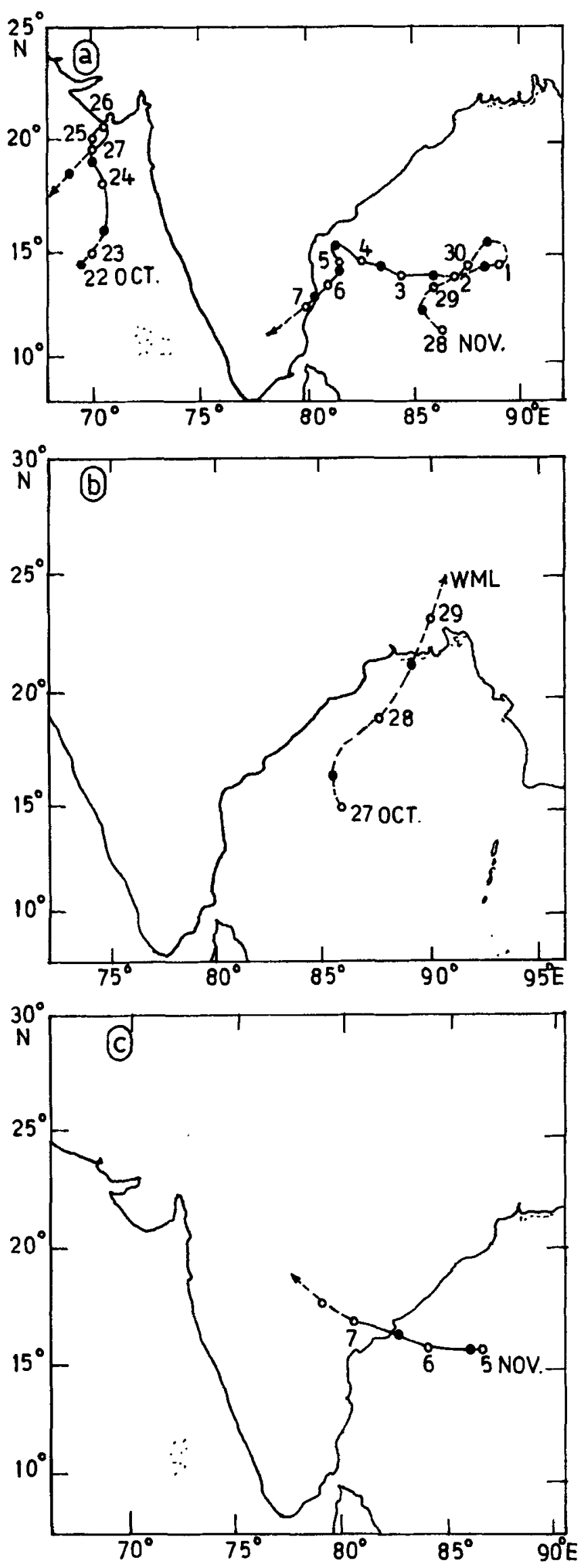

Figure 4. Track of depressions and cyclonic storms 1996.
- Depression in the Bay of Bengal (27th-29th October, 1996).

- Severe cyclonic storm in the Bay of Bengal (5th7th November, 1996).

- Severe cyclonic storm in the Bay of Bengal (27/ $11 / 96$ to $6 / 12 / 96)$.

- Development and movement of Inter-tropical Convergence Zone (ITCZ)/Equatorial troughs (ETs) (8th-28th October, 1996).

The track of the cyclonic storms/depressions mentioned above is shown in figure 4 . These tracks are prepared by the India Meteorological Department (IMD) by plotting the storm centres which are determined by making use of all available data related to the system, e.g., pressure, wind direction and speed as reported by the ships from the storm field, storm centre and intensity as estimated from cloud organization as seen in cloud imagery, radar observations etc.

\section{Discussions}

\subsection{Withdrawal of southwest monsoon - 1996}

The southwest monsoon - 1996 withdrew from western parts of west Rajasthan on September 15th. It further withdrew from remaining parts of west Rajasthan; some parts of Haryana and western parts of Punjab and Jammu and Kashmir on September 17th. It further withdrew from H.P., west U.P., Saurashtra and Kutch; remaining parts of Rajasthan, of Haryana including Delhi, of Punjab and Jammu and Kashmir; some parts of west M.P. by September 25th. Thereafter, the further withdrawal of SW monsoon was delayed due to the development of a depression over west central Bay of Bengal off south Andhra Pradesh (A.P.) coast on the morning of October 1st. It crossed the A.P. coast between Ongole and Kavali in the early night of the same day. Moving in a north westerly direction it weakened into a well marked low pressure area over south Maharashtra on the evening of October 2nd. The SW monsoon further withdrew from Maharashtra, northern parts of Karnataka and of A.P., remaining parts of M.P., East U.P., Bihar and most parts of Orissa by October 9th. The SW monsoon withdrew from the entire country on October 11th (figure 5).

Some of the selected dew point depression charts pertaining to the period of withdrawal of SW monsoon-1996 are reproduced in figure 6 . The withdrawal is seen in the southward shift of the area covered by $6 \mathrm{~K}$ dew point depression contour. Simultaneously the advance of the dry air is seen in the southward movement of the region covered by the dry profiles (dew point depression 11, 16 and 21). The development of a depression off A.P. coast, on October 1st, is seen in the westward extension of the dew point depression contour of $6 \mathrm{~K}$ over peninsula from where the SW monsoon had withdrawn earlier. 


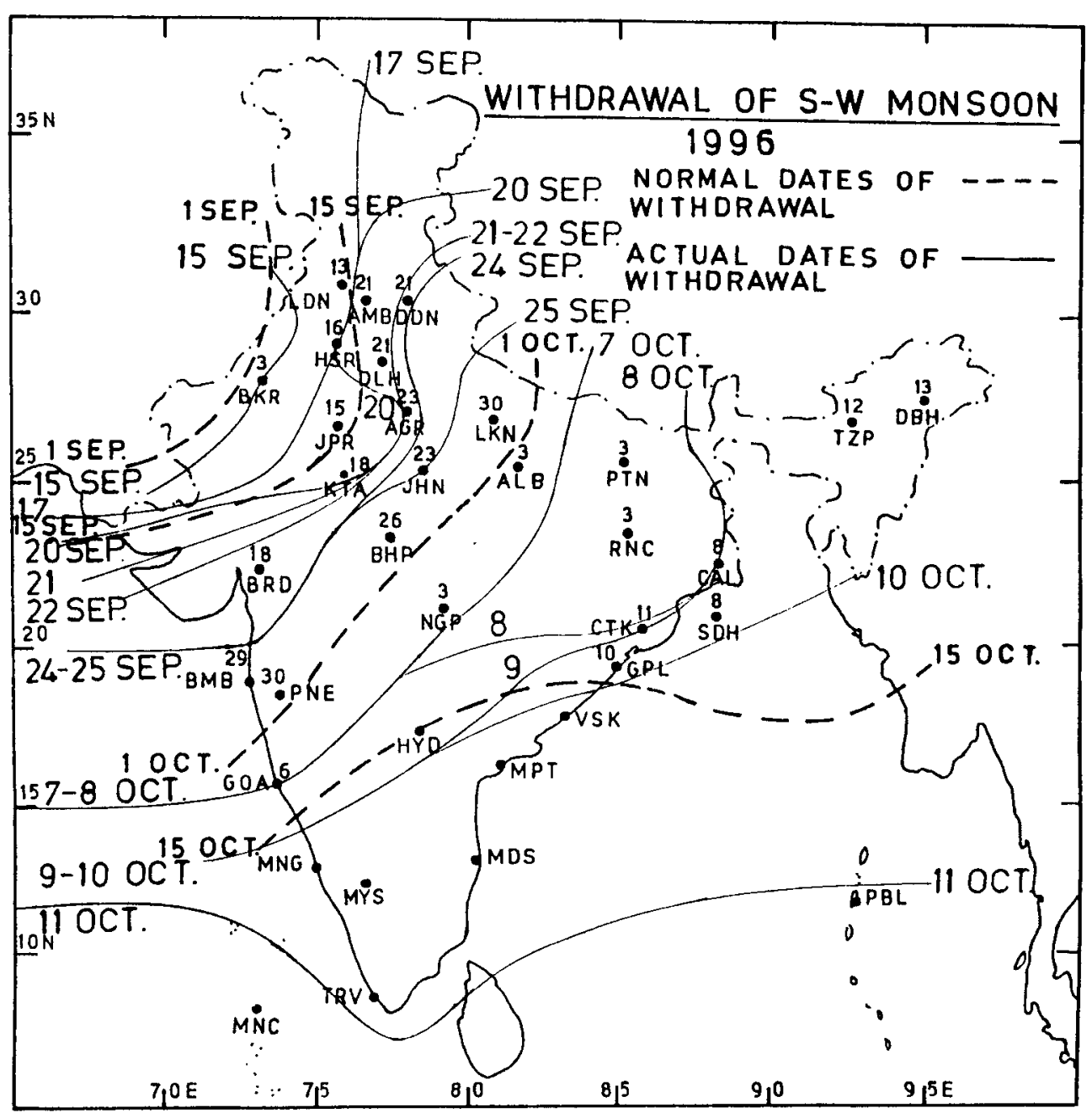

Figure 5. Dates of withdrawal of southwest monsoon - 1996 .

By October 11th, the day when the SW monsoon had been withdrawn from the entire country, no part of peninsular India is covered by the dew point depression contour of $6 \mathrm{~K}$.

Subsequent to the withdrawal of SW monsoon - 96, NE monsoon - 96 (October - December) was declared to have set in over south peninsula on October 11th. NE monsoon was active throughout its period. This was seen in the development of a number of synoptic systems in north Indian Ocean (Bay of Bengal and Arabian Sea). This is discussed in section 3.2. NE monsoon withdrew from the southernmost portion of Tamilnadu on December 23rd. By January 15th the area covered by humid profiles had moved close to the equator (figure $6(\mathrm{~g})$ ). Thus the southward movement of the humid tropical air associated with the withdrawal of SW monsoon and its replacement by dry continental air is clearly seen in the dew point depression charts.

\subsection{Development of synoptic systems and their movement}

During the period of northeast monsoon (October December) synoptic systems develop in southwest
Bay of Bengal. They generally move in a westerly direction and give rainfall over south peninsula. The year 1996 witnessed an active NE monsoon when a number of synoptic systems developed in the Bay of Bengal and gave rainfall over south peninsula which was in excess ( $>20 \%$ of normal) in coastal A.P. $(+27 \%)$, Rayalaseema $(+86 \%)$, Tamilnadu and Pondicherry $(+51 \%)$ and normal (rainfall within + or $-19 \%$ of normal) in south interior Karnataka $(+18 \%)$ and Kerala $(-9 \%)$. The development of individual systems and their movement as seen in the humidity profiles is discussed below:

\subsubsection{Severe cyclonic storm in Arabian Sea (22nd-27th October, 1996)}

A well marked low pressure area formed over SW Bay of Bengal and moved westward over south Andhra Pradesh on 19th October. Moving northwestwards it emerged in east central Arabian Sea on 21st October. It intensified into a severe cyclonic storm (SCS) and was located about $250 \mathrm{~km}$ south of Veraval on October 24th. It continued to move northwards till the morning of 25th October when it was centered 

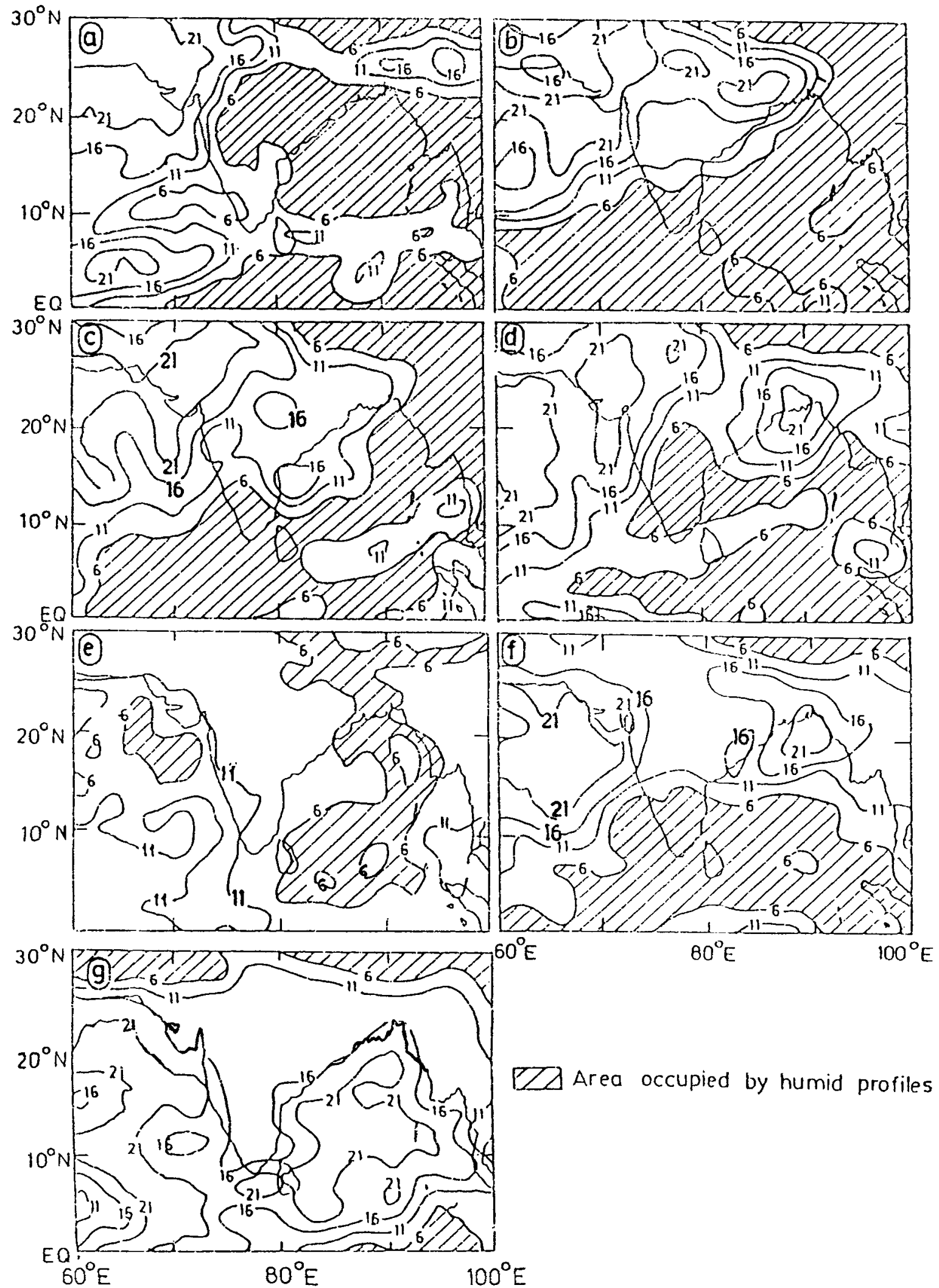

Figure 6. Dew point depression charts at $700 \mathrm{hPa}$ for selected dates during withdrawal of southwest monsoon - 1996; a: 15.9.96; b: 20.9 .96 ; c: $25.9 .96 ; \mathbf{d}: 1.10 .96$; e: $11.10 .96 ;$ f: $15.10 .96 ; \mathbf{g}: 15.1 .97$.

about $100 \mathrm{~km}$ south of Veraval. It weakened into a depression centered about $30 \mathrm{~km}$ SSW of Veraval on the morning of 26 th October. This system remained practically stationary till the morning of 27 th October.
Finally it moved westwards from Saurashtra coast, weakened into a low pressure area over Arabian Sea and became unimportant. The track of the system from 22nd-27th October is given in figure 4(a). 

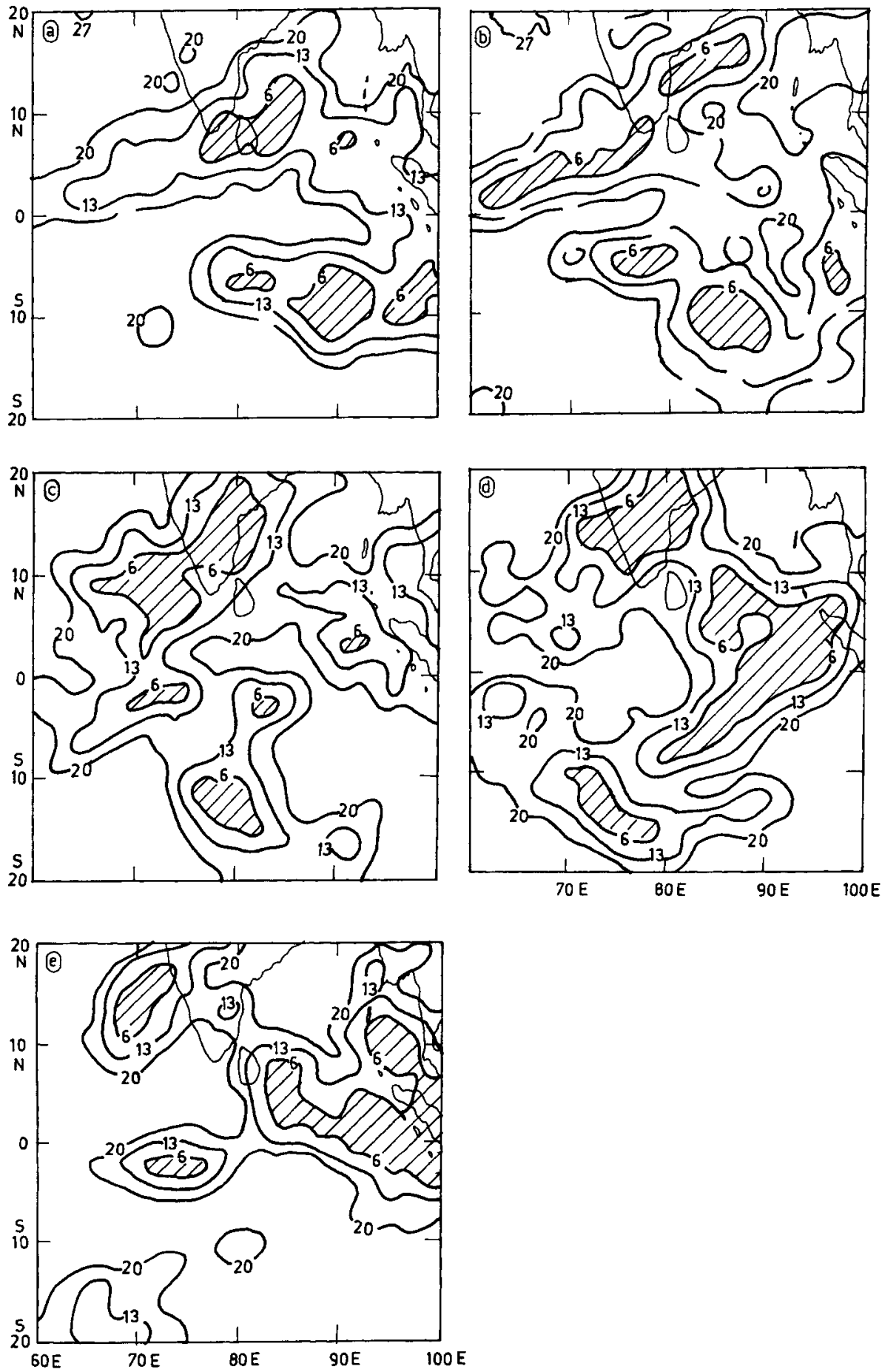

Figure 7. Dew point depression charts at $500 \mathrm{hPa}$ relating to the initial development of severe cyclonic storm in the Arabian Sea (16th-21st October, 1996): a: 16.10 .96 ; b: 17.10 .96 ; c: 18.10 .96 ; d: 19.10 .96 ; e: 22.10 .96 .

The development of the system could be seen in the humidity field earlier than that in the surface pressure field. The initial development occurred in an active northern hemispheric equatorial trough (NHET) and was first seen in upper levels (500 and $300 \mathrm{hPa})$. Events leading to the development of NHET are discussed in section 3.3. The dew point depression charts pertaining to the initial development are reproduced in figure 7 . The initial development of the system was seen on October 18th as a semi-circular region of $6 \mathrm{~K}$ dew point depression over eastern peninsula and parts of west central Bay of Bengal. Subsequent movement of the system northwestward and its emergence in east Arabian Sea on October 21st could be clearly seen in figure 7 . From October 21st onwards, the system could be seen at $700 \mathrm{hPa}$ also. This is discussed below.

The dew point depression charts from 21st-30th October are reproduced in figure 8 . The area covered by the dew point depression contour of $6 \mathrm{~K}$ clearly 

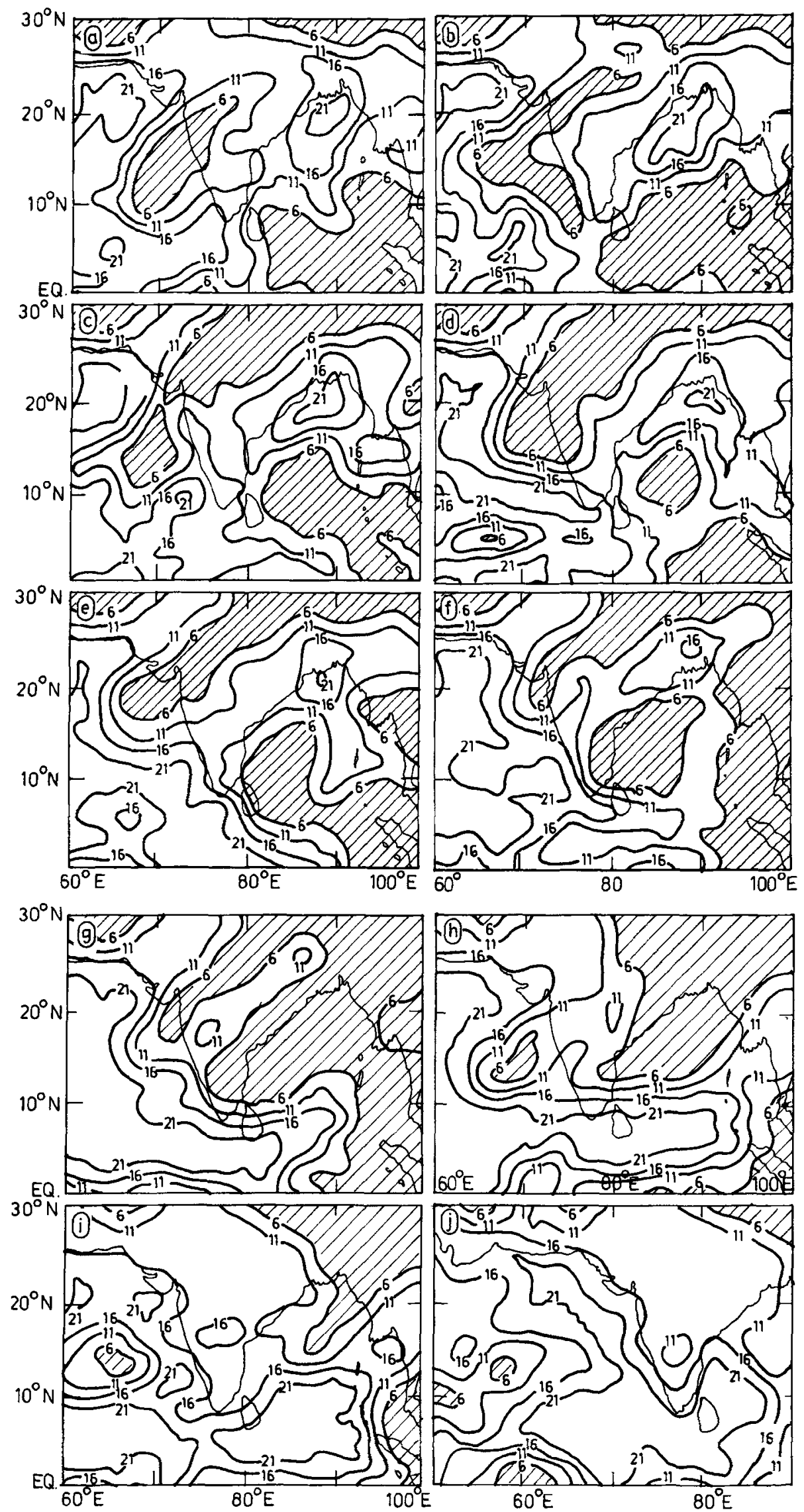

Figure 8. Dew point depression charts at $700 \mathrm{hPa}$ relating to the development and movement of the severe cyclonic storm in the Arabian Sea (21st-30th October 1996) and depression in Bay of Bengal (27th-29th October, 1996): a: 21.10.96; b: 22.10.96; c: 23.10 .96 ; d: $24.10 .96 ;$ e: 25.10 .96 ; f: $26.10 .96 ; \mathbf{g :} 27.10 .96 ; \mathbf{h}: 28.10 .96 ;$ i: $29.10 .96 ;$ j: 30.10 .96 . 
show the system's movement towards north up to 26th October. It remained close to Saurashtra coast till the morning of 27th October. Till 0000 UTC of $28 \mathrm{th}$ October the area occupied by dew point contour of $6 \mathrm{~K}$ had already moved southwards off the Maharashtra-Goa coast. Thereafter, the region moved further southwestwards and the area covered by $6 \mathrm{~K}$ dew point depression contour also reduced. On 30th October the region had already moved west of $60^{\circ} \mathrm{E}$ and the area covered was much reduced. Thus the area covered by dew point depression contour of $6 \mathrm{~K}$ closely followed the track of the system.

\subsubsection{Deep depression in the Bay of Bengal (27th-29th October)}

A depression formed over west central Bay of Bengal at about $430 \mathrm{~km}$ south east of Visakhapatnam on the morning of $27 \mathrm{th}$ October. The system moved in a north-northeasterly direction and intensified into a deep depression located about $400 \mathrm{~km}$ southsouthwest of Calcutta on the morning of 28th October. It crossed Bangladesh coast during midnight of 28th October, weakened into a depression and lay centered about $230 \mathrm{~km}$ northeast of Calcutta on 29th October. It became less important on October 30th. The track of the system is shown in figure $4(\mathrm{~b})$.

The dew point depression field from 23rd-30th October is shown in figure 8 . The development of the system on 24th October and its movement close to A.P. coast on the morning of 26 th October is seen as a nearly circular area of dew point depression contour of $6 \mathrm{~K}$ which covers west central Bay of Bengal and parts of coastal A.P.. Thereafter, the region covered by dew point depression contour of $6 \mathrm{~K}$ moved northeastwards. Thus the movement of the region of humid profiles closely followed the track of the system.

\subsubsection{Development of a severe cyclonic storm with a core of hurricane winds in the Bay of Bengal (5th-7th November)}

The INSAT imagery of 0600 UTC of 4 th November indicated the formation of a vortex near lat. $16.5^{\circ} \mathrm{N} /$ long. $91.0^{\circ} \mathrm{E}$. It further intensified and was classified as a depression at $1500 \mathrm{UTC}$ of November 4 th and at 0000 UTC of November 5th, it lay centred near lat. $16.0^{\circ} \mathrm{N} /$ long. $87.0^{\circ} \mathrm{E}$ about $650 \mathrm{~km}$ east of Machilipatnam. The system continued to move in a westerly direction and intensified into a severe cyclonic storm (SCS) with a core of hurricane winds by the afternoon of November 6th when it lay centred about $220 \mathrm{~km}$ ENE of Machilipatnam. It crossed A.P. coast about $50 \mathrm{~km}$ south of Kakinada during the night of November 6th. Moving in a WNWly direction, the system weakened into a low pressure area over Telangana by the evening of November 7 th. The track of the system is shown in figure $4(\mathrm{c})$.
The dew point depression charts pertaining to the SCS are reproduced in figure 9. At 0000 UTC of November 4th, the humid region was confined to the areas of Bay of Bengal to the east of $90^{\circ} \mathrm{E}$. By 0000 UTC of November 5th, a semi-circular region of humid profiles developed in west central Bay of Bengal. It came close to A.P. coast on November 6 th. By the morning of November 7th, it was located mainly over land. Thereafter, the humid region moved westward. By the morning of November 8th, the region of the humid profiles had moved over Telangana and adjoining areas of Maharashtra. Thus the movement of the region of humid profiles closely followed the track of the system.

\subsubsection{Development and movement of cyclonic storm with core of hurricane winds in the Bay of Bengal (27th November to 6th December)}

A well marked low pressure area formed in the evening of November 27th over southeast Bay of Bengal with the central region near lat. $9.0^{\circ} \mathrm{N} /$ long. $81.5^{\circ} \mathrm{E}$. Moving northwestward it concentrated into a depression on the morning of November 28th. Moving north and then northeastward it concentrated into a deep depression near lat. $11.5^{\circ} \mathrm{N} /$ long. $86.5^{\circ} \mathrm{E}$ on the morning of November 29th. It then moved northward and south-eastward and weakened into a depression on the morning of December 1st. Thus it took a complete loop over the central Bay of Bengal by the morning of December 1st and lay centered near lat. $14.5^{\circ} \mathrm{N} /$ long. $89.0^{\circ} \mathrm{E}$ at $0300 \mathrm{UTC}$. The system intensified again and attained the intensity of a CS at 0000 UTC of December 2nd and lay near lat. $14.0^{\circ} \mathrm{N} /$ long. $87.0^{\circ} \mathrm{E}$. Moving westward it further intensified into a SCS at 0300 UTC of December 3rd with the centre near lat. $14.5^{\circ} \mathrm{N} /$ long. $84.5^{\circ} \mathrm{E}$. It intensified into a SCS with the core of hurricane winds by 12 UTC of December 3rd and lay centred near lat. $14.5^{\circ} \mathrm{N} / \mathrm{long} .83 .5^{\circ} \mathrm{E}$. It moved close to the A.P. coast by 1200 UTC of December 4th. At this point the system showed weakening and disorganization in satellite pictures. It appeared that the upper portion of the system moved inland and the lower portion moved southward. It was relocated near lat. $14.5^{\circ} \mathrm{N} /$ long. $82.0^{\circ} \mathrm{E}$ as a SCS at $0300 \mathrm{UTC}$ of December 5 th. It made a loop moving clockwise from $04 / 1200$ to $05 / 1200$ UTC. Moving slowly in southwesterly direction, it came close to Chennai on the evening of December 6th. It crossed the coast between Chennai and Pondicherry and rapidly weakened into a low pressure area by the morning of December 7 th.

The humidity field associated with this system showed characteristics different than the systems discussed earlier: the system was not well defined in the humidity field at $700 \mathrm{hPa}$ throughout its life history. However, it was seen in the humidity field at 500 and also at $300 \mathrm{hPa}$. Accordingly the dew point depression chart is reproduced for $500 \mathrm{hPa}$ level (figure 10). On 

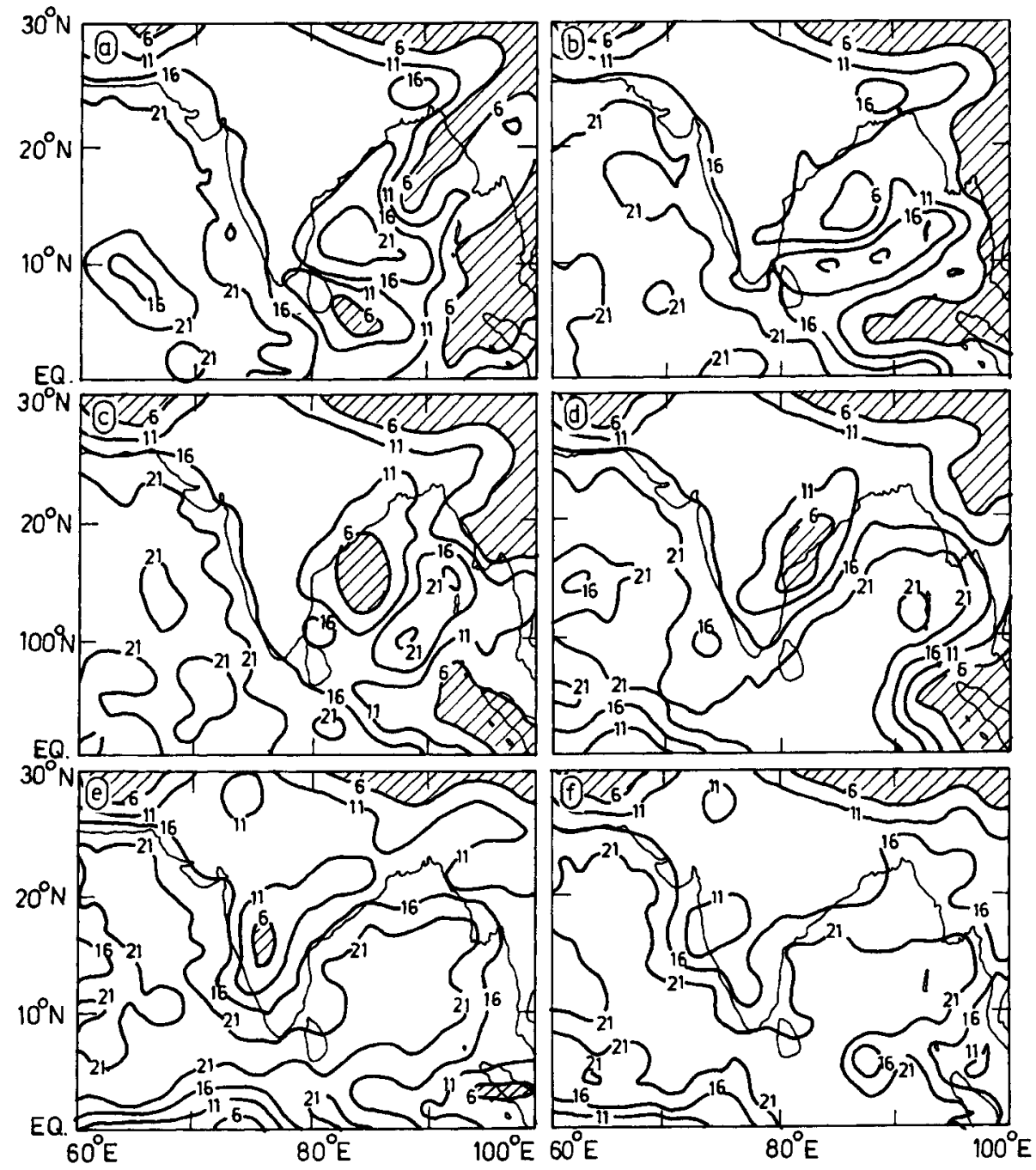

Figure 9. Dew point depression charts at $700 \mathrm{hPa}$ relating to the development and movement of severe cyclonic storm in the Bay of Bengal (4th-9th November, 1996): a: 4.11 .96 ; b: 5.11 .96 ; c: 6.11 .96 ; d: 7.11 .96 ; e: 8.11 .96 ; f: 9.11 .96 .

November 28th it was seen as a semi-circular region of $6 \mathrm{~K}$ dew point depression in central Bay of Bengal with the centre near $12.0^{\circ} \mathrm{N} / 87.0^{\circ} \mathrm{E}$. Thereafter it moved north and then east. On the morning of December 2nd it was seen as a circular region of $6 \mathrm{~K}$ dew point depression covering west central Bay of Bengal. On December 3rd it showed movement southward. It continued to move southward till December 5 th, when the region of $6 \mathrm{~K}$ dew point depression lay over central regions of south CAP and north Tamilnadu. By this time the area occupied by $6 \mathrm{~K}$ dew point depression contour had also reduced considerably. By the morning of December 6th a closed contour of dew point depression $13 \mathrm{~K}$ could be seen over the region. Here again the humid region associated with the CS as seen in the dew point depression field closely followed the track of the system.

\subsection{Development of Inter-tropical Convergence Zone (ITCZ)/Equatorial Troughs (ETs)}

The development of ITCZ was seen between the equator and $10^{\circ} \mathrm{S}$ on October $8 \mathrm{th}$. On this date the area covered by ITCZ was confined to the longitudes $60^{\circ} \mathrm{E}$ and $80^{\circ} \mathrm{E}$. A weak northern hemispheric equatorial trough (NHET) was also seen between $70^{\circ} \mathrm{E}$ and $80^{\circ} \mathrm{E}$ roughly along $10^{\circ} \mathrm{N}$. By October 11th a well marked east-west oriented ITCZ developed along 5 deg south. NHET continued to be present roughly along $10^{\circ} \mathrm{N}$. By October 12th the ITCZ showed weakening to the west of $80^{\circ} \mathrm{E}$ and extended up to $105^{\circ} \mathrm{E}$ in the east. To the north of the equator NHET became active between $60^{\circ} \mathrm{E}$ and $80^{\circ} \mathrm{E}$. By October 14th the main cloudiness shifted to the north of the equator. By October 17th NHET showed strengthening and extended from $50^{\circ} \mathrm{E}$ to $100^{\circ} \mathrm{E}$. Southern hemispheric equatorial trough (SHET) was also seen. The development of a vortex was seen in SHET. SHET weakened considerably by October 19th. A vortex developed in NHET over peninsula. The vortex in SHET became less marked on October 21st. The vortex over the peninsula emerged into the Arabian Sea and subsequently developed into a tropical cyclone. SHET remained weak, in general, during the subsequent two months, i.e., November and December 1996. SHET 


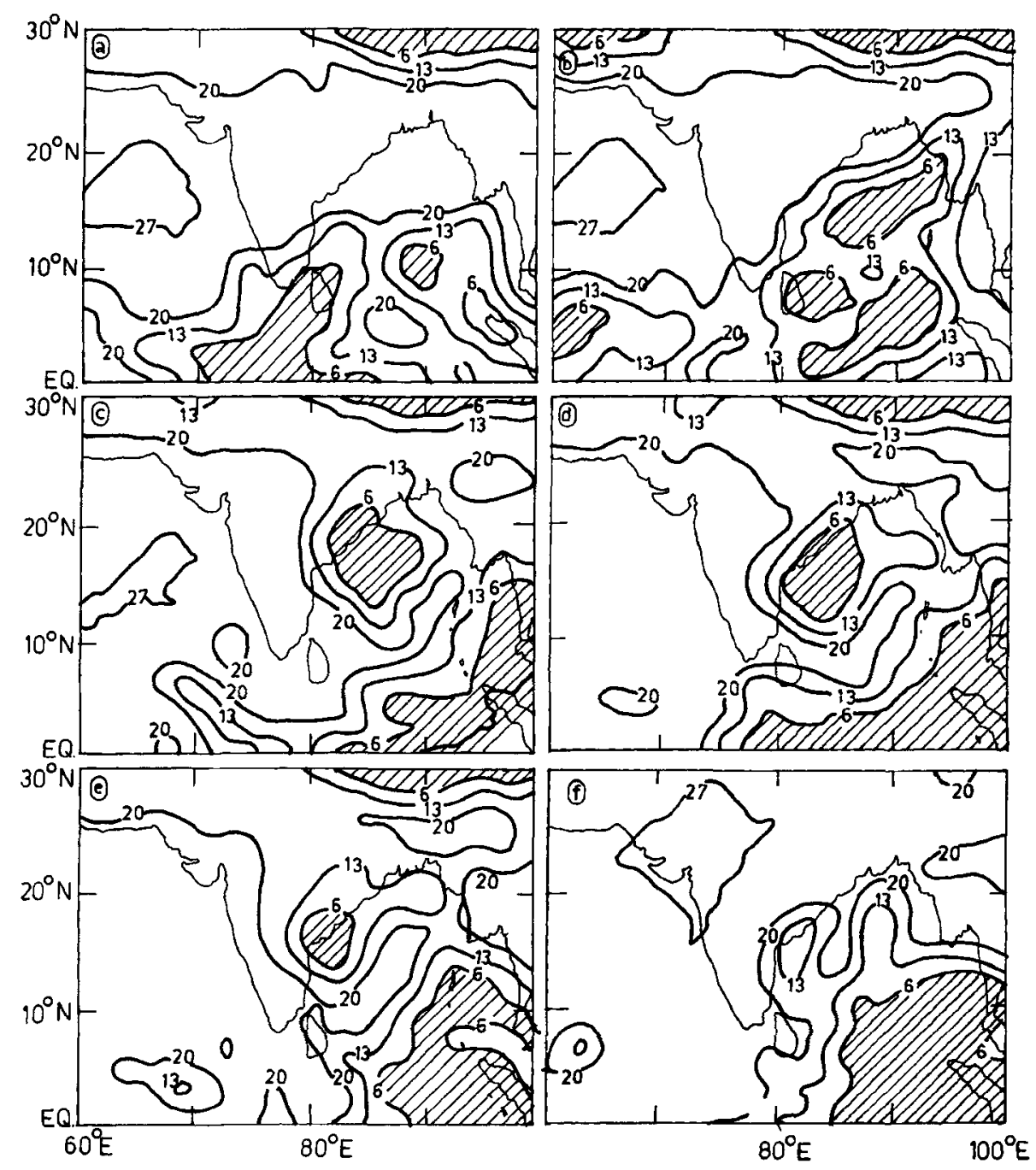

Figure 10. Dew point depression charts at $500 \mathrm{hPa}$ relating to the development and movement of severe cyclonic storm in the Bay of Bengal (27th November to 7th December, 1996): a: 27.11.96; b: 29.11.96; c: 2.12.96; d: 3.12.96; e: 4.12.96; f: 6.12.96.

remained generally active during all the weeks of the months of January and February 1997. Occasionally NHET also developed. While SHET remained confined to the areas between the equator and $10^{\circ} \mathrm{S}$, NHET was confined to the areas south of $5^{\circ} \mathrm{N}$. Both did not show movement to the north. In the month of March 1997 SHET developed on 4th, 5th and 9th. On the first two occasions it was confined to the areas west of $70^{\circ} \mathrm{E}$. On 9 th it was confined to the east of $75^{\circ} \mathrm{E}$. Thereafter, an E-W oriented SHET developed roughly along $5^{\circ} \mathrm{S}$ between $50^{\circ} \mathrm{E}$ and $90^{\circ} \mathrm{E}$ on $23 \mathrm{rd}$ March. This showed movement northwards and on March 31st it was occupying areas up to $10^{\circ} \mathrm{N}$ from $75^{\circ} \mathrm{E}$ to $100^{\circ} \mathrm{E}$. The development of equatorial troughs (ETs) and their movement was clearly seen in the dew point depression profiles. To illustrate this point the dew point depression field associated with the development of ITCZ/ETs in the month of October is discussed below.

The dew point depression field related to the development of SHET and NHET described above with the help of the satellite pictures is reproduced in figure 11. On October 8th a closed area of $6 \mathrm{~K}$ dew point depression was confined to the south of the equator and also some parts of south Bay of Bengal. On 9th, 10th and 11th October west to east oriented closed areas of $6 \mathrm{~K}$ dew point depression were seen on either side of the equator. On October 12th the area to the north of equator moved over south Arabian Sea and the area covered by $6 \mathrm{~K}$ dew point depression south of the equator showed movement to the north and occupied a much larger area extending up to $100^{\circ} \mathrm{E}$. By October 16 th east-west oriented cloudiness was mainly confined to the north of the equator. To the south of the equator it was confined to the areas east of $80^{\circ} \mathrm{E}$ only. By October 18th the area covered by $6 \mathrm{~K}$ dew point depression to the south of the equator was confined to a quasi-circular one between the equator and $15^{\circ} \mathrm{S}$ roughly along $80^{\circ} \mathrm{E}$. The area covered by $6 \mathrm{~K}$ dew point depression to the north covered parts of south peninsula and parts of east Arabian Sea off Kerala coast. By October 21st, the area enclosed by $6 \mathrm{~K}$ dew point depression had emerged into east Arabian Sea. The quasi-circular 

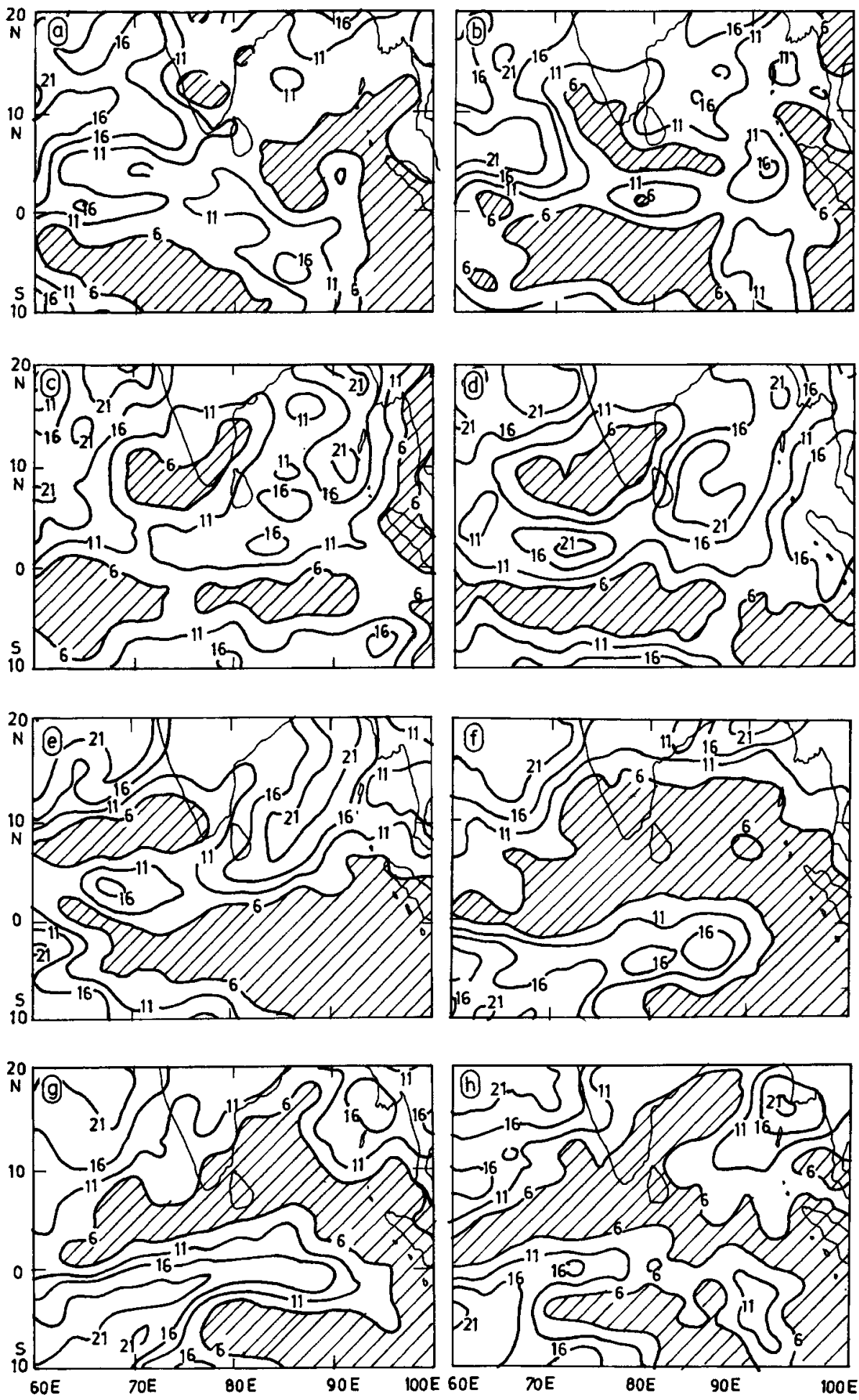

Figure 11. Dew point depression charts at $700 \mathrm{hPa}$ relating to the development of Inter-tropical Convergence Zone (ITCZ)/ Southern Hemisphere Equatorial Trough (SHET) and Northern hemispheric Equatorial Trough (NHET) (8th-20th October, 1996): a: 8.10 .96 ; b: 9.10 .96 ; c: 10.10 .96 ; d: 11.10 .96 ; e: 12.10 .96 ; f: 15.10 .96 ; g: 16.10 .96 ; h: 17.10 .96 .

area of $6 \mathrm{~K}$ dew point depression in south Indian Ocean had moved southwestward and was located near $16^{\circ} \mathrm{S}, 65^{\circ} \mathrm{E}$. Further movement of the area of $6 \mathrm{~K}$ dew point depression in the Arabian Sea is discussed in section 3.2.1.

In addition to the development of synoptic systems in north Indian Ocean (Bay of Bengal and Arabian
Sea) and ITCZ/ETs, the development and movement of tropical and extra-tropical cyclones over south Indian Ocean and troughs in the zonal westerlies, responsible for weather over north India during winter, were also monitored in the dew point depression field. It was noted that they were also tracked in the dew point depression field as was the case of the 
synoptic systems in the north Indian Ocean. However, the scope of the paper did not allow us to include the discussion on the movement of the humid region associated with these systems.

\section{Conclusions}

The examination of the humidity fields (dew point charts) obtained from INSAT infra red cloud imagery data has shown that the following could be clearly monitored in the dew point depression field:

- Withdrawal of southwest and northeast monsoons from the Indian sub-continent.

- Development, including the initial development, and movement of tropical systems (depressions and cyclonic storms).

- Development of ITCZ.

- Development and movement of equatorial troughs.

- Development and movement of troughs in zonal westerlies and extratropical cyclones over south Indian Ocean.
In order to examine the impact on the numerical analysis and forecast, the moisture data have been linked to the analysis and forecast system of IMD's Limited Area Model (LAM). The results on the impact of this additional humidity data on the forecast of development and movement of synoptic scale systems and rainfall over different regions of India are being studied and shall be reported separately.

\section{References}

Baba Atsushi 1987 Improvement in the estimation method of moisture data from satellite cloud soundings; JMA/NPD Tech. rep. No. 16 , pp. 54

Mills G A and Davidson N E 1987 Tropospheric moisture profiles from digital IR satellite imagery: System description and analysis/forecast impact; Australia Met. Mag. 35 108118

Prasad O and Rao A V R K 1991 Estimation of relative humidity profiles from INSAT digital IR cloud imagery data; Mausam 42 287-294

Prasad O, Prasad S and Kelkar R R 1996 Humidity profiles from INSAT IR digital cloud imagery data. (to appear in the Bulletin of Indian Meteorological Society: Vayu Mandal). 